\title{
Effects of Severe Plastic Deformation on the Mechanical Properties of Welded ST37-2 Steel
}

\author{
Abubaker Sahhal \\ Mechanical Engineering Department \\ Karabuk University \\ Karabuk, Turkey \\ abubaker_ahmad@yahoo.de
}

\author{
Mustafa Gunay \\ Mechanical Engineering Department \\ Karabuk University \\ Karabuk, Turkey \\ mgunay@karabuk.edu.tr
}

\begin{abstract}
Cold treatment techniques are used to enhance the mechanical properties of metal alloys, whose most important characteristics are strength, roughness, and microstructure. The aim of this research is to test the effect of Conventional Shot Peening (CSP) and Severe Shot Peening (SSP) on the mechanical properties of $S T 37-2$ steel. The results of the experiments showed enhancements in surface roughness and tensile strength. However, shot peening decreased the ductility of the metal and caused changes in its microstructure that are indicated in the XRF and XRD tests. Results' data are provided as an original contribution to the literature while they are compared with the existing data.
\end{abstract}

\section{Keywords-ST37-2; shot peening; severe plastic deformation}

\section{INTRODUCTION}

Surface treatment using cold techniques is widely used to enhance the mechanical properties of metal alloys [1]. Shot peening is one of these processes that has an impact on surface roughness, residual stresses, microstructure, and folding of the metal [2]. The effects of plastic deformations resulting from welding or shot peening can be beneficial or have adverse effects on its strength and ductility [3]. Severe plastic deformation (SPD) is formed in metals through processes such as hydrostatic extrusion which deform the metal at low temperatures. SPD results into a fine crystalline structure that differs from the crystallographic structure of the original metal or alloy, through forming micrometric and submicrometric subgrains in the coarse grain of the original material [4]. The advantages of SPD on the performance and mechanical properties derive from its ability to achieve deformations in the microstructure through fine grains, which reflects on the performance results of hardness and yield stress to saturation levels [5]. The disadvantages of SPD are embodied mainly in the decreased ductility and decreased metal ability to undergo plastic deformation under stress [6].

\section{RESEARCH AIM AND METHODS}

\section{A. Research Aim}

The main aim of the current research is to test the effects of SPD through electric arc welding and shot peening on the mechanical properties and microstructure of ST37-2. It is expected for these processes to affect the microstructure and the homogeneity of the specimens, thus altering their mechanical properties.

\section{B. Material and Sample Preparation}

The alloy used in this experiment is ST37-2 (metal content percentages are shown in Table I). The alloy has $0.2 \%$ carbon and $0.011 \%$ nitrogen maximum content. The tensile strength of the alloy ranges between 360 and $460 \mathrm{MPa}$ while it yields at $235 \mathrm{MPa}$ with a minimum elongation of $25 \%$ [7].

TABLE I. CHEMICAL COMPOSITION OF ST37-2 (\%) [8]

\begin{tabular}{|c|c|c|c|c|c|c|c|c|}
\hline Fe & Mn & Si & Al & Cr & Cu & Ni & P & S \\
\hline 98.7012 & 1.0916 & 0.0641 & 0.0408 & 0.0285 & 0.0253 & 0.0235 & 0.0158 & 0.0091 \\
\hline
\end{tabular}

After cleaning the steel plates, the samples were initially prepared with dimensions of $400 \mathrm{~mm}$ length, $200 \mathrm{~mm}$ width, and $10 \mathrm{~mm}$ thickness. Plate pairs were welded with an arc welding device with a $10 \mathrm{~mm}$ welding to form a single plate, as shown in Figure 1. The welding slag was removed with an electric grinding machine. Using a plasma cut, the welded plates were cut into six samples, as shown in Figure 2. Three specimens were prepared for tensile testing and three for fatigue testing. The sample dimensions followed the ASTM specifications of the testing specimens. Figure 3 shows the specimens for tensile and fatigue testing.

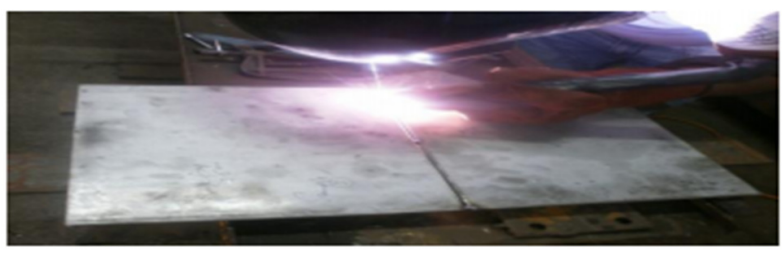

Fig. 1. Arc welding of steel plates

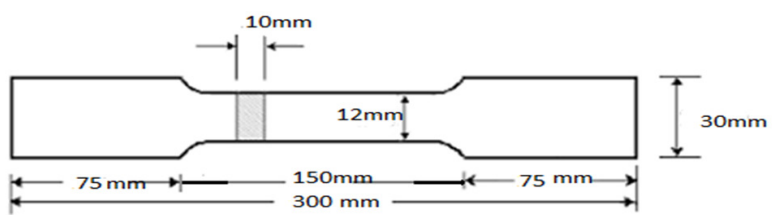

Fig. 2. Testing specimens schematic 
(a)

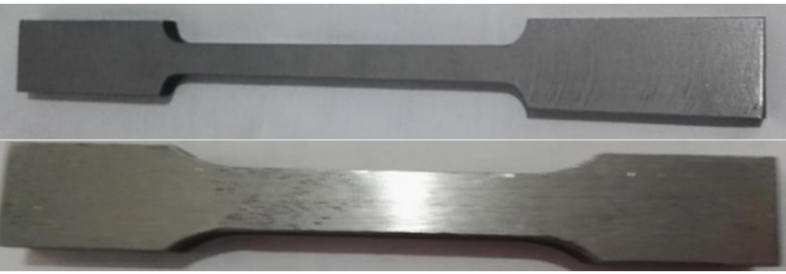

Fig. 3. Samples for (a) tensile testing and (b) fatigue testing

Four out of the six specimens were shot peened with two Almen intensities, A12-14 (CSP) and A28-30 (SSP). The shot peening conditions are shown in Table II.

TABLE II. CONDITIONS OF SHOT PEENING FOR CSP (CONVENTIONAL) AND SSP (SEVERE)

\begin{tabular}{|c|c|c|c|c|c|}
\hline $\begin{array}{c}\text { Almen } \\
\text { intensity }\end{array}$ & $\begin{array}{c}\text { Shot } \\
\text { size }\end{array}$ & Coverage & $\begin{array}{c}\text { Duration } \\
\text { (sec) }\end{array}$ & $\begin{array}{c}\text { Air pressure } \\
\text { (psi) }\end{array}$ & $\begin{array}{c}\text { Arc height } \\
\text { (mm) }\end{array}$ \\
\hline A12-14 (CSP) & S230 & $200 \%$ & 10 & 30 & 0.13 \\
\hline A28-30 (SSP) & S230 & $200 \%$ & 15 & 60 & 0.29 \\
\hline
\end{tabular}

The process of shot peening involves striking the samples with tiny particles with a specific pressure that acts as a hammer on a small area of the surface in order to create indentations or dimples [9]. The process energizes the particles with kinetic energy which is absorbed by the metal surface [10], which then attempts to restore its original condition [11]. The main target of using shot peening is to increase the hardness and fatigue resistance of the samples, while reducing tension [12]. Figures 4-5 show the metal surfaces after using the two types of shot peening. The top picture shows shot peening with A12-14 Almen, while the bottom picture shows shot peening with A28-30 Almen.

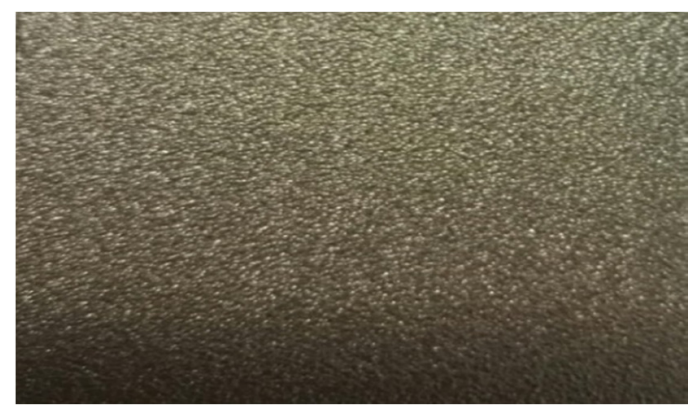

Fig. 4. Surface of ST37-2 after shot peening, A12-14

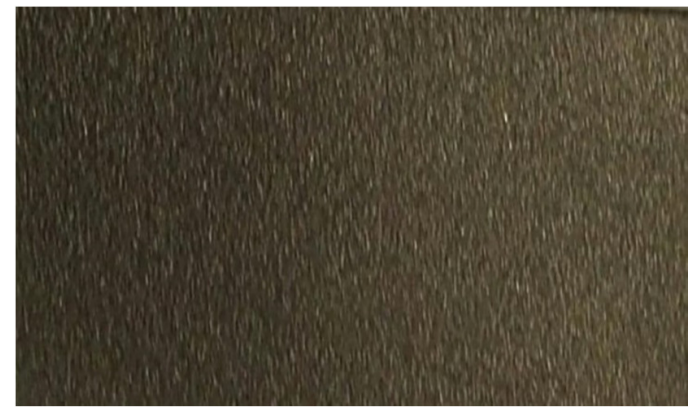

Fig. 5. Surface of ST37-2 after shot peening, A28-30

\section{RESULTS AND DISCUSSION}

\section{A. Surface Roughness}

Three samples were tested for surface roughness: untreated, type A12-14 shot peening, and type A28-30 shot peening. Average roughness (Ra), root mean square roughness (Rq) and average maximum height of roughness profile $(\mathrm{Rz})$ were obtained. Figures 6-8 show the plots of the testing outputs. The results show a significant increase in roughness between the untreated metal and the CSP cases, while more increase in roughness can be observed in the SSP cases. These results are in accordance with the literature. Authors in [13] increased hardness and roughness for engine bladed with shot peening, while authors in [14] showed that the increase in shot peening severity increased surface roughness in ZK60 alloy.

TABLE III. SURFACE ROUGHNESS VALUES

\begin{tabular}{|c|c|c|c|c|}
\hline Material & Almen intensity & Ra & Rq & Rz \\
\hline ST37-2 STEEL & A12-14 (CSP) & 6.568 & 8.174 & 32.267 \\
\hline ST37-2 STEEL & A28-30 (SSP) & 7.466 & 8.907 & 34.432 \\
\hline ST37-2 STEEL & As received & 0.198 & 0.253 & 1.432 \\
\hline
\end{tabular}

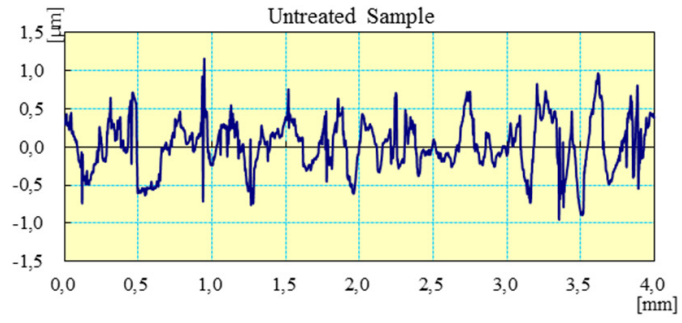

Fig. 6. Roughness test profiles (untreated)

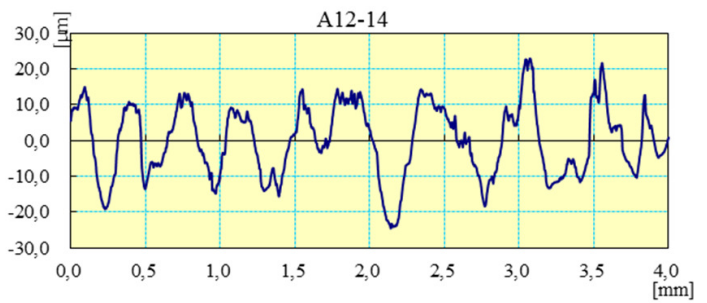

Fig. 7. Roughness test profiles (A12-14)

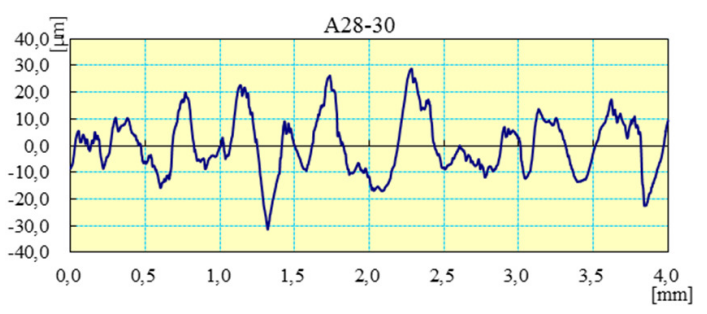

Fig. 8. Roughness test profiles (A28-30)

\section{B. Tensile Test}

The force required to break a specimen and its elongation were measured through a tensile strength test according to ASTM D-638, ASTM D-3039, and ASTM C-297 standards. As shown in Table IV, the first sample treated with type A2830 shot peening retained the yield strength of $360 \mathrm{MPa}$, while the ultimate tensile strength was enhanced by less than $5 \%$. The 
elongation of the first sample decreased by around $5 \%$. The changes are considered insignificant for the first sample. However, the second sample treated with type A28-30 shot peening showed more significant results as yield strength increased by $19.7 \%$, ultimate tensile strength increased by $22.8 \%$, and elongation decreased by at least $46.8 \%$. The results indicate increased tensile strength accompanied with decreased ductility of the sample. Samples treated with shot peening type A12-14 and those that were not treated with shot peening showed insignificant changes in yield strength and ultimate tensile strength. Figures 9-11 show the plots of the tensile test results. Elongations have decreased at least by $1.2 \%$ to $27.2 \%$, confirming the effect of shot peening on the ductility of the alloy. These results are based on standard range values of ST37-2. However, other studies of the alloy showed yield strength and ultimate tensile strength values of $235 \mathrm{MPa}$ and $436.8 \mathrm{MPa}$ respectively for untreated samples. Therefore, the results of the current study are considered significant in comparison to such results [15]. The results also show that SSP with type A28-30 showed enhanced tensile strength in comparison with CSP which confirms the results of the literature in this aspect [16]. Generally, shot peening showed enhanced strength in comparison with untreated samples [13].

TABLE IV. RESULTS OF TENSILE STRENGTH T TESTING

\begin{tabular}{|c|c|c|c|c|}
\hline Material & Almen intensity & YS (MPa) & UTS (MPa) & Elongation (\%) \\
\hline & $\mathrm{A} 28-30$ & 360 & 482 & 23.7 \\
\cline { 2 - 5 } & $\mathrm{A} 28-30$ & 431 & 565 & 13.3 \\
\cline { 2 - 5 } St37-2 steel & $\mathrm{A} 12-14$ & 352 & 478 & 24.7 \\
\cline { 2 - 5 } & A12-14 & 357 & 472 & 20.7 \\
\cline { 2 - 5 } & As received & 349 & 469 & 18.2 \\
\cline { 2 - 5 } & As received & 348 & 469 & 23.2 \\
\hline
\end{tabular}

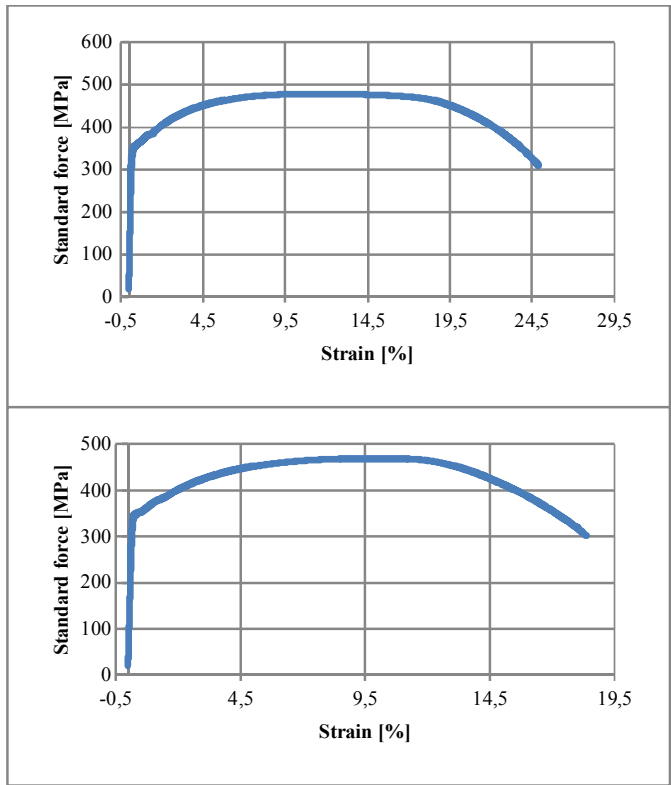

Fig. 9. Tensile test plots for A12-14

\section{Microhardness Test}

Vickers microhardness test was conducted by applying a load of $1 \mathrm{~kg}$ for $15 \mathrm{~s}$ by a ball indicator. Measurements were taken by a calibrated optical microscope for the stress in $\mathrm{MPa}$, as shown in Table V. Shot peening increased microhardness from its original value of 150 for ST37-2 by averagely $21.1 \%$ to $47.6 \%$ [17]. Authors in [18] showed that microhardness for low carbon steel has an average value of 92 , which proves that the obtained hardness values in the current study are a huge enhancement.

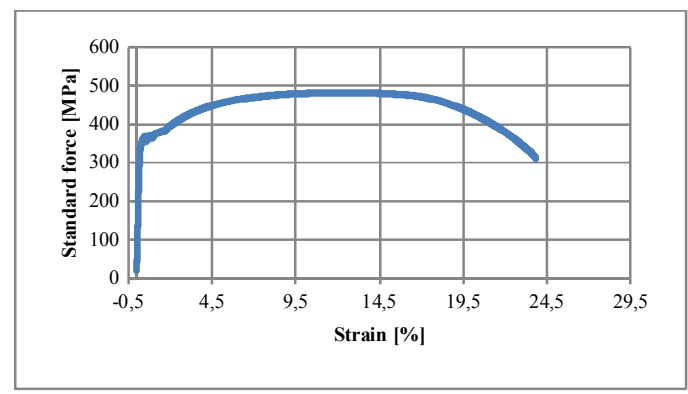

Fig. 10. Tensile test plot for A28-30

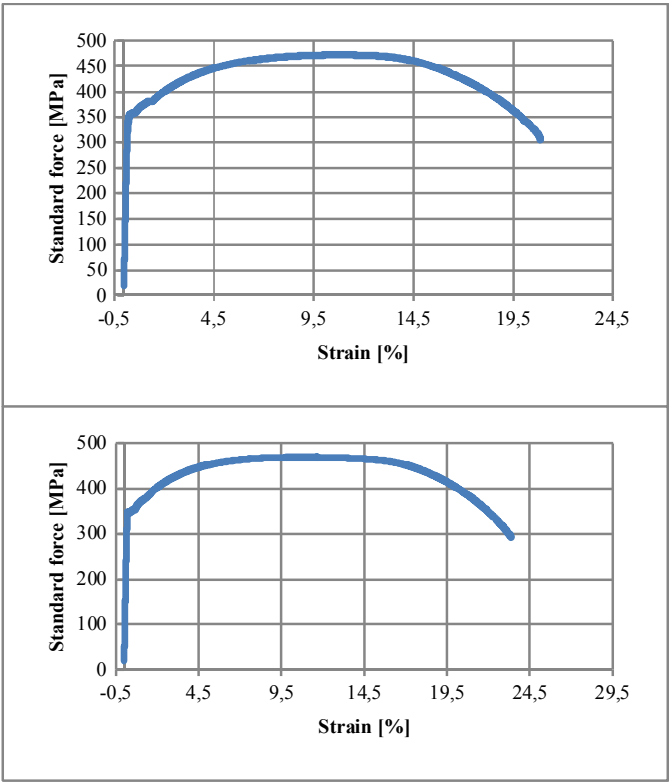

Fig. 11. Tensile plots for the untreated samples

TABLE V. VICKERS MICROHARDNESS TEST VALUES

\begin{tabular}{|c|c|c|c|c|}
\hline Almen intensity & Value (1) & Value (2) & Value (3) & Average \\
\hline $\mathbf{A 2 8 - 3 0}$ & 222 & 224 & 218 & 221.33 \\
\hline $\mathbf{A 1 2 - 1 4}$ & 189 & 192 & 188 & 189.67 \\
\hline As received & 183 & 181 & 181 & 181.67 \\
\hline
\end{tabular}

\section{XRF Analysis}

$\mathrm{X}$-Ray Fluorescence (XRF) is a microscopy method that is used to measure the concentration of metals in a specific area. The method depends on the interaction between the x-ray arrays with the matter by dislodging electrons from atoms, measuring the resulting energy and correlating it with a specific element [19]. As seen from the results of the XRF (Table VI), the mass percentage of each metal component has been changed through shot peening, while the analysis depth ranged between 0.0009 and $0.0355 \mathrm{~mm}$. 
TABLE VI. XRF ANALYSIS OF ST37-2

\begin{tabular}{|c|c|c|c|c|c|c|c|}
\hline Component & Result & Unit & EI line & $\begin{array}{c}\text { Det. } \\
\text { Limit }\end{array}$ & Intensity & $\begin{array}{c}\text { w/o } \\
\text { normal }\end{array}$ & $\begin{array}{c}\text { Analyzing } \\
\text { depth } \\
\text { (mm) }\end{array}$ \\
\hline $\mathrm{Al}$ & 0.0408 & Mass\% & 0.00204 & $\mathrm{Al}-\mathrm{KA}$ & 0.3807 & 0.0418 & 0.0009 \\
\hline $\mathrm{Si}$ & 0.0641 & Mass\% & 0.00205 & Si-KA & 0.6215 & 0.0656 & 0.0013 \\
\hline $\mathrm{P}$ & 0.0158 & Mass\% & 0.00103 & $\mathrm{P}-\mathrm{KA}$ & 0.4290 & 0.0161 & 0.0018 \\
\hline $\mathrm{S}$ & 0.0091 & Mass\% & 0.00072 & $\mathrm{~S}-\mathrm{KA}$ & 0.2240 & 0.0093 & 0.0025 \\
\hline $\mathrm{Cr}$ & 0.0285 & Mass\% & 000432 & $\mathrm{Cr}-\mathrm{KA}$ & 0.6336 & 0.0292 & 0.0230 \\
\hline $\mathrm{Mn}$ & 1.0916 & Mass\% & 0.00870 & Mn-KA & 20.4876 & 1.1177 & 0.0265 \\
\hline $\mathrm{Fe}$ & 98.7012 & Mass\% & 0.02378 & Fe-KA & 2319.6146 & 101.0629 & 0.0355 \\
\hline $\mathrm{Ni}$ & 0.0235 & Mass\% & 0.00802 & Ni-KA & 0.2879 & 0.0241 & 0.0066 \\
\hline $\mathrm{Cu}$ & 0.0253 & Mass\% & 0.00556 & $\mathrm{Cu}-\mathrm{KA}$ & 0.3890 & 0.0259 & 0.0104 \\
\hline
\end{tabular}

\section{E. XRD Analysis}

In order to identify crystalline material in the samples that were treated with shot peening, X-Ray powder Diffraction (XRD) analysis was used. Figure 12 shows the peaks of three samples, which are identical in phase pattern and position, while differing in intensity. The matching patterns and positions are signs of error absence in positioning during the experiment. The slightly higher broadening at 64.85 and 82.27 degrees indicates minor nanocrystalline ceria. The three peaks shown in the figure show that changes in the micro-strains have occurred with shot peening and their intensities decreased with the increase of the severity of the deformation through shot peening in the metal.

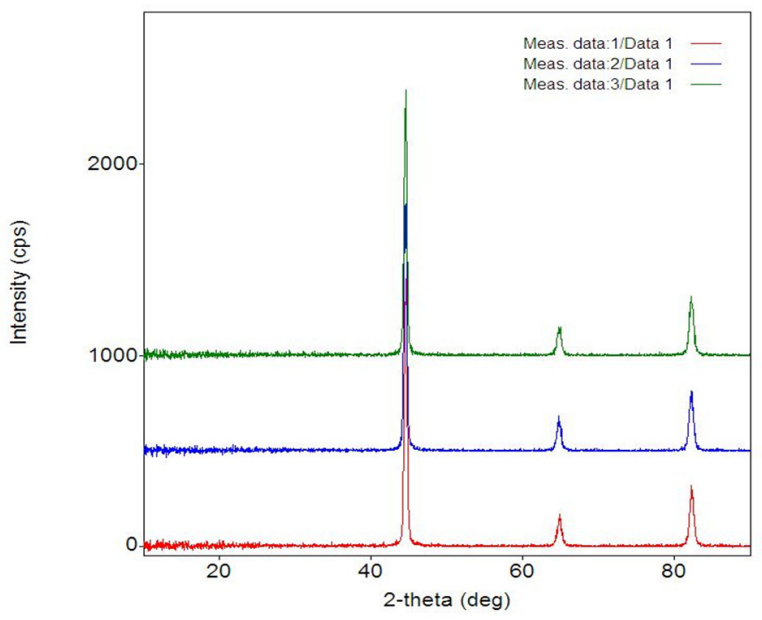

Fig. 12. Diffractogram of XRD analysis

\section{F. Optical Microscope}

Two specimens were investigated with an optical microscope (Figure 13) to study the microstructure and mechanical changes of the shot peening treatment. Shot peening with CSP A12-14 Almen intensity affected a thin layer with minimum influence, while shot peening with SSP A28-30 Almen intensity had a higher intensive influence to a thicker layer. In the SSP case, an intrinsic structure is observed. The ferrite and perlite phases are clear with SSP A28-30 [20].

\section{G. Scanning Electron Microscopy (SEM)}

As shown in Figure 14, the specimens treated with shot peening were tested with SEM. Both A12-18 and A28-30 Almen intensities yielded plastic deformations. Disturbances were increased in the SSP case, while it created more intense bumps and pits. Layer thickness was increased by $24.4 \%$ in the SSP case in comparison with the CSP case. The homogeneity of the alloy did not seem to be affected in both samples by shot peening, however the increase in hardness as confirmed by the hardness test is reflected by the formation of connected deformed structures [21].

(a)

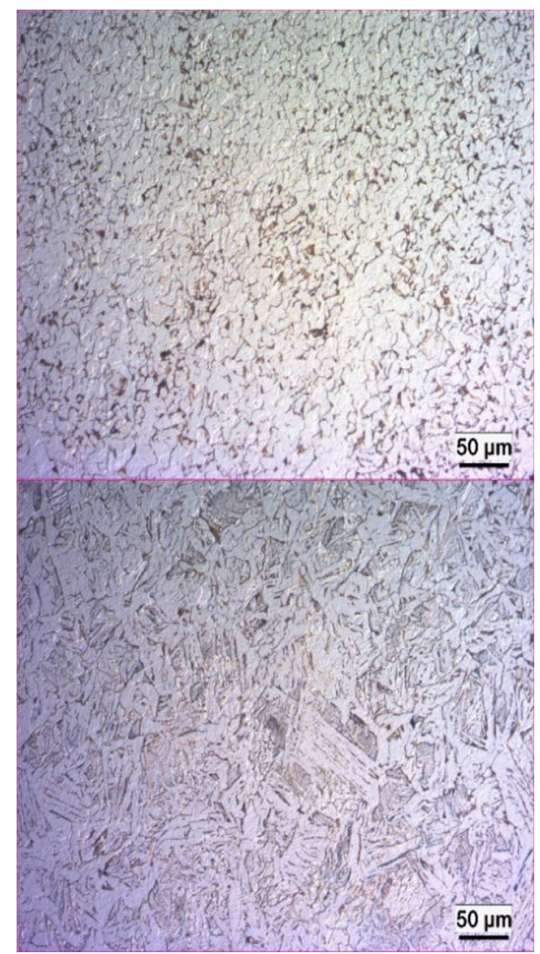

Fig. 13. Optical microscope images for shot peened samples: (a) CSP A1214 , (b) SSP A28-30 (bottom)

(a)

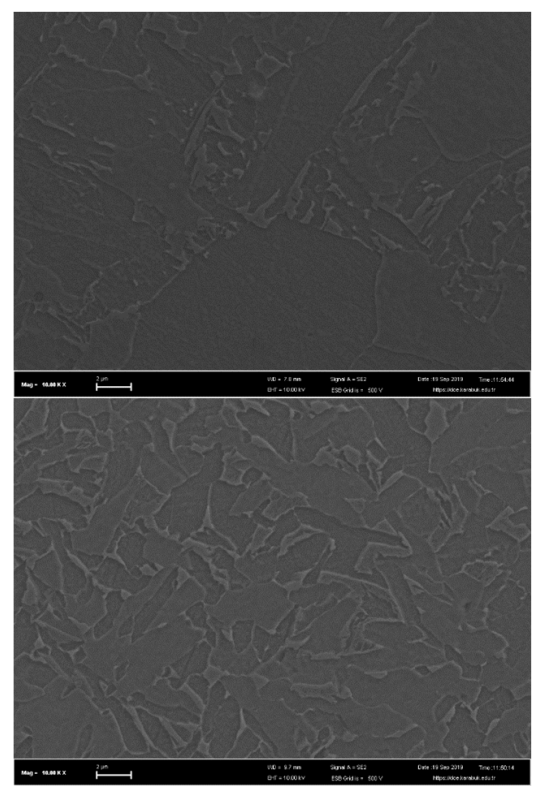

Fig. 14. FESEM images of plastic deformed layer of shot peened specimens: (a) CSP A12-14 (top-layer thickness=7.8 $\mu \mathrm{m}$ ), (b) SSP A28-30 (bottom-layer thickness $=9.7 \mu \mathrm{m})$ 


\section{CONCLUSION}

The enhancement of alloy properties can be achieved through cold techniques such as shot peening, targeting improvements in strength, roughness, and microstructure. The current research aims to investigate the effects of conventional (CSP) and severe (SSP) shot peening on the mechanical properties of ST37-2 steel through their comparison with untreated specimens, and performing an arc weld as severe plastic deformation (SPD). Two Almen intensities were used, A12-14 and A28-30. The surface roughness values showed substantial increases in $\mathrm{Ra}, \mathrm{Rq}$ and $\mathrm{Rz}$ values between A12-14 and untreated ST37-2 samples, while a higher increase in roughness was achieved with A-23-30 shot peening. The tensile strength results show enhancements in yield strength and ultimate tensile strength values reaching up to $19.7 \%$ and $22.8 \%$ with SSP, while elongation decreased up to $27.2 \%$ confirming the decrease in ductility with shot peening. The hardness of the alloy increased in treated samples and the changes in microstructure were exhibited by XRF and XRD analyses. Deformation intensities were investigated with optical microscopy and were found to have increased while a layer thickness increase in the SSP case (in comparison with the CSP case) was observed. Some data confirm the past literature findings, while the research contributes to the relevant literature with original data.

\section{REFERENCES}

[1] L. Singh, R. A. Khan, M. L. Aggarwal, "Effect of shot peening on hardening and surface roughness of nitrogen austenitic stainless steel", International Journal of Engineering Science and Technology, Vol. 2, No. 5, pp. 818-826, 2010

[2] A. Kubit, M. Bucior, W. Zielecki, F. Stachowicz, "The impact of heat treatment and shot peening on the fatigue strength of 51CrV4 steel", Procedia Structural Integrity, Vol. 2, pp. 3330-3336, 2016

[3] Y. Ma, M. Yang, F. Yuan, X. Wu, "A review on heterogeneous nanostructures: A strategy for superior mechanical properties in metals", Metals, Vol. 9, Article ID 598, 2019

[4] M. Umemoto, Y. Todaka, K. Tsuchiya, "Formation of nanocrystalline structure in steels by air blast shot peening", Materials Transactions, Vol. 44, No. 7, pp. 1488-1493, 2003

[5] O. Unal, E. Maleki, "Shot peening optimization with complex decisionmaking tool: Multi criteria decision-making", Measurement, Vol. 125, pp. 133-141, 2018

[6] D. Kumar, S. Idapalapati, W. Wang, S. Narasimalu, "Effect of surface mechanical treatments on the microstructure-property-performance of engineering alloys", Materials (Basel), Vol. 12, No. 16, Article ID 2503, 2019

[7] A. Ampaiboon, O. U. Lasunon, B. Bubphachot, "Optimization and prediction of ultimate tensile strength in metal active gas welding", The Scientific World Journal, Vol. 2015, Article ID 831912, 2015

[8] R. Ranji, A. H. Zakeri, "Mechanical properties and corrosion resistance of normal strength and high strength steels in chloride solution", Journal of Naval Architecture and Marine Engineering, Vol. 7, pp. 93-100, 2010

[9] I. Karademir, O. Unal, S. Ates, H. Gokce, M. Gok, "Effect of severe plastic deformation on wear properties of aluminum matrix composites", Acta Physica Polonica A, Vol. 131, No. 3, pp. 487-489, 2017

[10] O. Unal, I. Zulcic, R. Varol, I. Karademir, S. Ates, "Novel type shot peening applications on railway axle steel", Journal of Mineral Metal and Material Engineering, Vol. 2, pp. 1-5, 2016

[11] O. Unal, R. Varol, "Surface nanostructuring of AISI 1017 by severe shot peening”, Research and Reports on Metals, Vol. 1, pp. 1-4, 2017

[12] O. Unal, A. C. Karaoglanli, Y. Ozgurluk, K. M. Doleker, E. Maleki, R. Varol, "Wear behavior of severe shot peened and thermally oxidized commercially pure titanium”, Engineering Design Applications, Vol. 5, pp. 461-470, 2019

[13] M. A. Omari, H. M. Mousa, F. M. Al-Oqla, M. Aljarrah, "Enhancing the surface hardness and roughness of engine blades using the shot peening process", International Journal of Minerals, Metallurgy and Materials, Vol. 26, No. 8, pp. 999-1004, 2019

[14] W. Liu, J. Ding, P. Zhang, C. Zhai, W. Ding, "Effect of shot peening on surface characteristics and fatigue properties of T5-treated ZK60 alloy", Materials Transactions, Vol. 50, No. 4, pp. 791-798, 2009

[15] A. Thakur, G. Aregawi, "Effect of heat treatment on mechanical properties and microstructure of ST 37-2 rear trailing arm”, International Journal of Current Engineering and Technology, Vol. 9, No. 1, pp. 8091, 2019

[16] E. Maleki, G. H. Farrahi, "Modelling of conventional and severe shot peening influence on properties of high carbon steel via artificial neural network", International Journal of Engineering, Vol. 30, No. 11, pp. 382-393, 2017

[17] M. Yazdani, M. R. Toroghinejad, S. M. Hashemi, "Investigation of microstructure and mechanical properties of St37 steel-Ck60 steel joints by explosive cladding", Journal of Materials Engineering and Performance, Vol. 24, No. 10, pp. 4032-4043, 2015

[18] F. O. Sonmez, A. Demir, "Analytical relations between hardness and strain for cold formed parts", Journal of Materials Processing Technology, Vol. 186, pp. 163-173, 2007

[19] A. B. M. Helaluddin, R. S. Khalid, M. Alaama, S. A. Abbas, "Main analytical techniques used for elemental analysis in various matrices", Tropical Journal of Pharmaceutical Research, Vol. 15, No. 2, pp. 427434, 2016

[20] M. I. Mohamed, "Studies of the properties and microstructure of heat treated $0.27 \% \mathrm{C}$ and $0.84 \% \mathrm{Mn}$ steel", Engineering, Technology \& Applied Science Research, Vol. 8, No. 5, pp. 3484-3487, 2018

[21] S. H. Abro, A. Chandio, A. R. Jamali, S. A. Shah, "Influence of austenite phase transformation on existing microstructure of low C-Mn steel", Engineering, Technology \& Applied Science Research, Vol. 8, No. 6, pp. 3525-3529, 2018 